\title{
Use of an Open-Frame Hinged Surgical Table to Restore Segmental Lumbar Lordosis After Posterior Column Osteotomy
}

\author{
ADITYA VEDANTAM, MD, TERENCE VERLA, MD, RORY R. MAYER, MD, MICHAEL R. RABER, MD, \\ ALEXANDER E. ROPPER, MD \\ Department of Neurosurgery, Baylor College of Medicine, Houston, Texas
}

\section{INTRODUCTION}

Maintaining lumbar lordosis and sagittal balance is an important consideration for patients undergoing lumbar fusion. ${ }^{1-3}$ The use of interbody grafts and posterior column osteotomies (PCOs) can increase segmental lumbar lordosis from a posterior approach. Compression to close the PCO shortens the posterior column and increases the segmental lumbar lordosis. ${ }^{4-6}$ Aggressive compression across pedicle screws, however, is associated with increased stress on the screws and can lead to intraoperative screw breakout, particularly in patients with poor bone mineral density. ${ }^{7}$ Efforts to reduce the stress on the screws during closure of the osteotomy may avoid these intraoperative complications and can help maintain the integrity of instrumentation.

The open-frame hinged surgical table allows surgeons to manipulate lumbar lordosis during prone spine surgery. ${ }^{8,9}$ By adjusting the angle of the hinged surgical table, surgeons can decrease or increase segmental lumbar lordosis during decompression and instrumentation, respectively. While decreasing lumbar lordosis can facilitate decompression as with a traditional Wilson frame, increasing lumbar lordosis can help restore sagittal alignment prior to fixation. This technique is potentially useful for closure of a PCO to restore lumbar lordosis. ${ }^{10}$ Prior reports have mentioned extension of the surgical bed to close PCOs for patients with ankylosing spondylitis. ${ }^{11,12}$ However, it is not known whether the hinged surgical table is equivalent to compression across the screws to close a PCO in patients with degenerative spine disease undergoing lumbar interbody fusions.
We evaluated the change in segmental lumbar lordosis in patients undergoing lumbar interbody fusion with PCO on a hinged surgical table.

\section{MATERIALS AND METHODS}

In this retrospective study, consecutive patients undergoing PCO and lumbar interbody fusion from November 2016 to November 2018 were reviewed. Institutional review board approval was obtained from Institution Blinded for Review for the study. The need for informed consent was waived given the retrospective study design and use of deidentified data. All surgeries were performed by the senior author (A.E.R.). From November 2016 to November 2017, we compressed across the pedicle screws to close the PCO (group 1). This was done with a standard screw head compressor, and the amount of force used to the compress was variable and at the surgeon's discretion. From December 2017 on, we used an open-frame hinged surgical table (ProAxis and Trios Surgical Table, Mizuho OSI, Union City, California) to close the PCO without manual compression across the pedicle screws (group 2). In this study, we compared the 2 surgical techniques by analyzing preoperative clinical data, intraoperative radiographs, and early postoperative outcomes.

\section{Surgical Technique}

In the initial cohort (group 1), patients were positioned on a Jackson table, and pedicle screws were placed using a standard technique. For the PCO, we performed complete bilateral facetectomies, a large laminectomy, and partial pars resection and removed the ligamentum flavum. This resulted in complete bony removal between the 
Table. Demographic and clinical preoperative and postoperative data.

\begin{tabular}{|c|c|c|c|}
\hline & $\begin{array}{c}\text { Group } 1 \\
\text { (Jackson } \\
\text { Table) }\end{array}$ & $\begin{array}{c}\text { Group } 2 \\
\text { (Hinged Surgical } \\
\text { Table) }\end{array}$ & $P$ Value \\
\hline $\mathrm{N}$ & 22 & 31 & \\
\hline Age & $63.4 \pm 13.1$ & $64.0 \pm 9.9$ & $.80^{\mathrm{a}}$ \\
\hline Sex, male/female & $13 / 9$ & $13 / 18$ & $.2^{\mathrm{b}}$ \\
\hline Body mass index & $28.9 \pm 4.2$ & $31.2 \pm 4.5$ & $.06^{\mathrm{a}}$ \\
\hline \multicolumn{4}{|l|}{ Surgical indications } \\
\hline Spondylolisthesis & 19 & 19 & \\
\hline Adult spine deformity & 3 & 8 & \\
\hline Recurrent lumbar disk & - & 2 & \\
\hline Facet cyst & - & 1 & \\
\hline Pseudoarthrosis & - & 1 & \\
\hline $\begin{array}{l}\text { Estimated blood loss, } \\
\text { mean } \pm \mathrm{SD}\end{array}$ & $459.2 \pm 428.6$ & $475 \pm 502.9$ & $.91^{\mathrm{a}}$ \\
\hline \multicolumn{4}{|l|}{ Revision surgery, n (\%) } \\
\hline None & $13(59.1)$ & $17(54.8)$ & $.63^{\mathrm{c}}$ \\
\hline Prior decompression & $7(31.8)$ & $8(25.8)$ & \\
\hline Prior fusion & $2(9.1)$ & $6(19.4)$ & \\
\hline \multicolumn{4}{|l|}{ Levels } \\
\hline L1-L2 & 1 & 1 & \\
\hline L2-L3 & 2 & 5 & \\
\hline L3-L4 & 7 & 10 & \\
\hline L4-L5 & 10 & 19 & \\
\hline L5-S1 & 6 & 7 & \\
\hline $\begin{array}{l}\text { Interbody height, mean } \\
\quad \pm \mathrm{SD}, \mathrm{mm}\end{array}$ & $10.9 \pm 1.0$ & $11.2 \pm 2.2$ & $.41^{\mathrm{a}}$ \\
\hline $\begin{array}{l}\text { Length of stay in } \\
\text { hospital, mean } \pm \mathrm{SD} \text {, } \\
\text { days }\end{array}$ & $4.2 \pm 2.4$ & $5.5 \pm 2.8$ & .11 \\
\hline
\end{tabular}

rostral and caudal pedicles over both the midline and the foramen. Once the interbody graft was placed via a transforaminal approach, rods were positioned across the screws, and the osteotomy was closed by compressing the screws and locking the rod.

In the second cohort (group 2), the patients were positioned on the hinged surgical table. The table was flexed at $10^{\circ}-24^{\circ}$ to increase lumbar kyphosis and improve exposure for decompression and placement of pedicle screws and interbody grafts (Figure 1A). After the PCO was performed and the interbody graft was placed, the table was returned to the neutral position $\left(0^{\circ}\right.$; Figure 1B). This closed the osteotomy adequately and allowed compression across the interbody graft. No manual compression

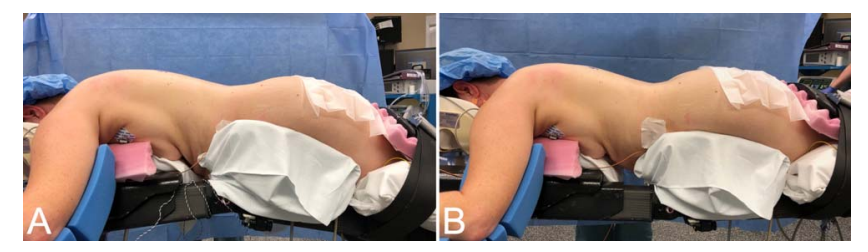

Figure 1. Patient postioned on hinged surgical table with table flexed at $20^{\circ}(\mathrm{A})$ and table at $0^{\circ}(\mathrm{B})$.

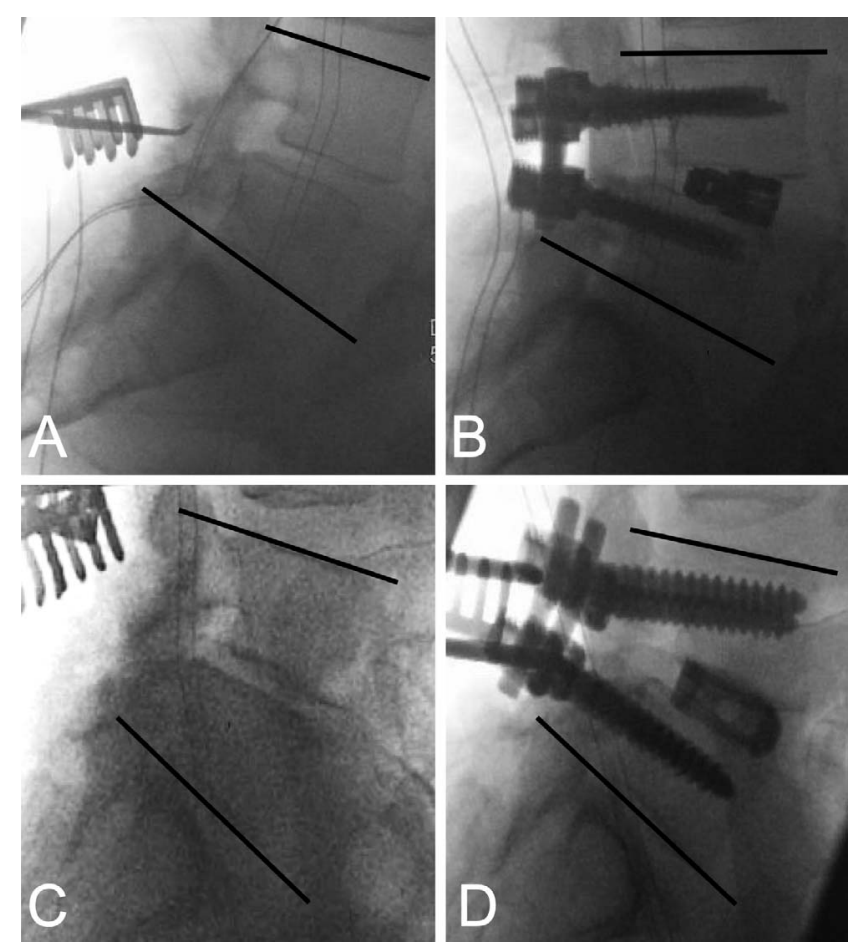

Figure 2. Intraoperative radiographs showing measurement of Cobb angles for patients undergoing L4-L5 interbody fusion with posterior column osteotomy (PCO). (A, B) Patient positioned on a Jackson table; intraoperative sagittal alignment shown before decompression (C) and after manual compression of screws to close the PCO (D). (C, D) Patient positioned on a hinged surgical table with table flexed at $20^{\circ}$ prior to decompression (A) and table at $0^{\circ}$ after closure of the PCO (B).

across the screws was required. The rods were then placed and locked.

A variety of interbody devices were used in this study based on surgeon preference for that particular case. All patients underwent free-running EMG monitoring during the surgery.

\section{Radiographic Evaluation}

Radiographic measurements on intraoperative fluoroscopic images were made using GE PACS 2.0 (GE Medical Systems, Chicago, Illinois). The segmental Cobb angle at the level of the osteotomy was measured between the superior endplate of the superior level and the inferior endplate of the inferior level (Figure 2). At the L5-S1 level, the superior endplate of S1 was used to measure the segmental Cobb angle. For group 1, Cobb angles were measured on the initial image (before instrumentation) and on the final images after compression across the screws and placement of the rod. For group 2, intraoperative lateral fluoroscopic images were obtained when the table was flexed (initial image) and when the table was in neutral position (final image) after rods were placed and locked. For 
patients undergoing multilevel fusion and posterior column osteotomies at more than level, each level was measured and analyzed separately.

\section{STATISTICAL METHODS}

Descriptive statistics were used for demographic and clinical data. Categorical data were analyzed using the chi-square test and the Fisher exact test. The mean difference in Cobb angles between the initial and final images at each surgical level was calculated. SPSS 23.0 (IBM, Armonk, NY) was used for analysis, and statistical significance was set at $P<.05$.

\section{RESULTS}

A total of 58 patients were reviewed during the study period, and 5 patients were excluded because they did not have intraoperative radiographs available for review. Sixty-eight segmental levels were assessed for 53 patients in the final study group. The Table shows the demographic and clinical data for the 2 groups. There were no statistically significant differences for the preoperative variables between the 2 groups. All patients underwent lumbar interbody fusion and PCO for degenerative spine disease, and the majority of patients underwent surgery for the first time $(n=30$, $56.6 \%$ ). The most common surgical level was L4-L5 (group 1: $40.9 \%$; group 2: $48.4 \%$ ). For patients in group 2, the surgical table was flexed from $10^{\circ}$ to $24^{\circ}$, the majority of cases being performed with the table at $20^{\circ}(\mathrm{n}=24,77.4 \%)$. No changes in intraoperative neuromonitoring recordings were noted when changing the table angle during surgery. Complications were seen in 7 patients. In group 1, 1 patient had a durotomy. In group 2, 4 patients had a durotomy, 1 patient had an intraoperative interbody graft extrusion unrelated to table angle, and 1 patient had a postoperative pulmonary embolism. No patient had new neurological deficits postoperatively.

\section{Radiographic Data}

The mean change in segmental Cobb angle was $5.8^{\circ} \pm 5.3^{\circ}(P<.01)$ for the entire study. There was a statistically significant increase in mean segmental Cobb angles after closure of the osteotomy for both group $1(P<.01)$ and group $2(P<.01)$. There was no statistically significant difference between the 2 groups for the initial segmental Cobb angle (group

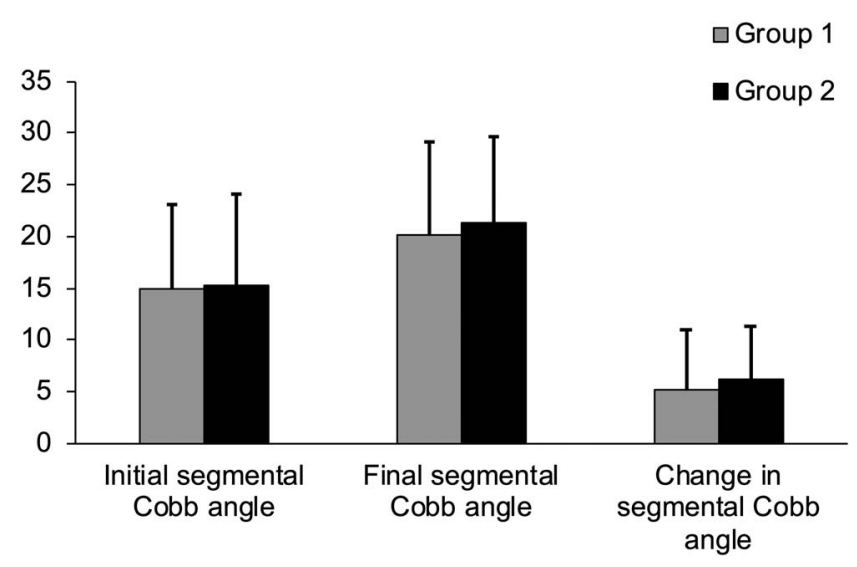

Figure 3. Bar graph showing changes in intraoperative segmental Cobb angles after closure of posterior column osteotomy in patients undergoing lumbar fusion with Jackson table (group 1) and hinged surgical table (group 2). No statistically significant differences were found between the 2 groups.

1: $15 \pm 8.1$; group 2: $15.2 \pm 8.9 ; P=.94)$ or the final segmental Cobb angle (group 1: $20.1 \pm 8.9$; group 2: $21.3 \pm 8.3 ; P=.58)$. The change in segmental Cobb angle after closure of the osteotomy was not statistically significant between the 2 groups (group 1: $5.1 \pm 5.7$; group 2: $6.2 \pm 5.1 ; P=.44$ ) (Figure 3).

\section{DISCUSSION}

The study focuses on the use of a hinged surgical table to close a PCO in patients undergoing instrumented lumbar fusion. Changing the table from a flexed to a neutral position closed the osteotomy and produced a significant increase in segmental lumbar lordosis, and these results showed no statistically significant differences when compared with traditional manual compression to close a PCO.

Appropriate patient positioning during lumbar fusion surgery is necessary to ensure that physiological sagittal alignment is achieved during fixation. Patients positioned on the standard Jackson table, which is commonly used for lumbar fusion surgery, show increased lumbar lordosis as compared with those positioned in the knee-chest position. ${ }^{13,14}$ However, increased lordosis can make decompression more difficult due to overlap of the lumbar laminae. Sebastian et $\mathrm{al}^{8}$ found that approximately $20^{\circ}$ of motion was obtained using a hinged surgical table, and this was equivalent to physiological motion allowed during active motion. The hinged surgical table can flex in a bidirectional manner to increase or decrease the lordosis intraoperatively. In the initial few patients, we used a smaller angle of flexion, but with experience, we 
found that $20^{\circ}$ was the optimal angle for most patients-for decompression and to close the osteotomy without the need for compression across the pedicle screws. However, this flexion angle for the table can be modified to suit each individual patient.

While patient positioning on the operative table can assist deformity correction, a well-performed PCO is essential to create segmental lumbar lordosis and avoid kyphosis in the setting of interbody fusion. As previously described, the PCO involves a complete bilateral facetectomy, laminotomy, removal of the ligamentum flavum, and closure of the osteotomy. ${ }^{15}$ In this study, the osteotomy was closed in a controlled manner with the hinged surgical table without the need for compression across the screws. Van Royen et $\mathrm{al}^{7}$ showed that screw breakout during compression across pedicle screws may be related to poor bone mineral density, calcification of disks, and bridging osteophytes. The hinged surgical table ensures motion across multiple vertebral segments to close the osteotomy and reduces excessive stress on the pedicle screws at a single level. The PCO has been shown to create $7^{\circ}-$ $10^{\circ}$ of segmental lordosis, with lesser degree of correction in older patients. ${ }^{4,15}$ In the present study, the mean change in segmental angle was $6.3^{\circ} \pm 5.4^{\circ}$, which was similar to the values reported by Dorward et $\mathrm{al}^{15}$ for older patients. In this study, we evaluated 2 techniques to close the PCO, and it was not unexpected that there was no statistically significant difference in the change in segmental angles between the 2 groups because both groups of patients underwent a similar technique for decompression. Closure of the PCO using the hinged surgical table was found to be noninferior to aggressive manual compression across the pedicle screws.

The link between intraoperative and postoperative sagittal spine alignment has been investigated previously. Although maintenance of intraoperative lumbar lordosis is an important goal of lumbar fusion surgery, prior authors have shown that intraoperative segmental lumbar lordosis is not necessarily maintained postoperatively. ${ }^{16,17}$ Salem et $\mathrm{al}^{17}$ indicated that improvements in total lumbar lordosis on postoperative imaging may be related to the extent of decompression. The use of the hinged surgical table may facilitate more efficient lumbar decompression, and this could independently improve total lumbar lordosis; however, this needs to be evaluated in future studies. It is also important to highlight the risk for neurological complications when increasing kyphosis using the hinged surgical table, particularly in patients with severe kyphosis and stenosis. ${ }^{18}$ In the present study, we focused on patients undergoing lumbar fusion surgery and used free-running electromyograms for all patients. Although we had no significant neurophysiological changes in this series, it is reasonable to consider monitoring somatosensory and motor-evoked potentials for patients undergoing thoracic fusion with the hinged surgical table.

This study is limited by its retrospective design, relatively small sample size, unequal numbers of patients in the 2 groups, variety of interbody grafts used, nonuniform compressive force used in the first cohort, and lack of postoperative standing radiographs to evaluate the maintenance of segmental lumbar lordosis. To limit the variability in surgical technique, we focused on consecutive cases performed by a single surgeon; however, there may have been some variability in the segmental angles due to the position of the interbody graft, which was not measured. Overall, this study details the use of a hinged surgical table as an adjunct surgical technique to provide controlled closure of a PCO in the lumbar spine.

\section{CONCLUSIONS}

The open-frame hinged surgical table aids decompression and restoration of intraoperative segmental lumbar lordosis in patients undergoing PCO and lumbar interbody fusion.

\section{REFERENCES}

1. Kepler CK, Rihn JA, Radcliff KE, et al. Restoration of lordosis and disk height after single-level transforaminal lumbar interbody fusion. Orthop Surg. 2012;4(1):15-20.

2. Kim MK, Lee S-H, Kim E-S, Eoh W, Chung S-S, Lee CS. The impact of sagittal balance on clinical results after posterior interbody fusion for patients with degenerative spondylolisthesis: a pilot study. BMC Musculoskelet Disord. 2011;12:69. doi: 10.1186/1471-2474-12-69.

3. Schwab FJ, Blondel B, Bess S, et al. Radiographical spinopelvic parameters and disability in the setting of adult spinal deformity: a prospective multicenter analysis. Spine. 2013;38(13):E803-E812.

4. Cho K-J, Bridwell KH, Lenke LG, Berra A, Baldus C. Comparison of Smith-Petersen versus pedicle subtraction osteotomy for the correction of fixed sagittal imbalance. Spine. 2005;30(18):2030-2037; discussion 2038.

5. Han S, Hyun S-J, Kim K-J, et al. Multilevel posterior column osteotomies are not inferior for the correction of rigid 
adult spinal deformity compared with pedicle subtraction osteotomy. World Neurosurg. 2017;107:839-845. doi: 10.1016/ j.wneu.2017.08.116

6. Robertson PA, Armstrong WA, Woods DL, Rawlinson JJ. Lordosis recreation in transforaminal and posterior lumbar interbody fusion: a cadaveric study of the influence of surgical bone resection and cage angle. Spine. 2018;43(22):E1350E1357.

7. van Royen BJ, de Kleuver M, Slot GH. Polysegmental lumbar posterior wedge osteotomies for correction of kyphosis in ankylosing spondylitis. Eur Spine J. 1998;7(2):104-110.

8. Sebastian AS, Ahmed A, Vernon B, et al. The effect of an adjustable hinged operating table on lumbar lordosis during lumbar surgery. Spine. 2017;43(4):1.

9. Jones KE, Hunt MA, Martin CT, Polly DW. Controlled pedicle subtraction osteotomy site closure using flexible hingepowered operating table. Oper Neurosurg. 2019;17(5):E214E218.

10. Kim K-T, Park K-J, Lee J-H. Osteotomy of the spine to correct the spinal deformity. Asian Spine J. 2009;3(2):113-123.

11. Arun R, Dabke HV, Mehdian H. Comparison of three types of lumbar osteotomy for ankylosing spondylitis: a case series and evolution of a safe technique for instrumented reduction. Eur Spine J. 2011;20(12):2252-2260.

12. Chang K-W, Chen Y-Y, Lin C-C, Hsu H-L, Pai K-C. Closing wedge osteotomy versus opening wedge osteotomy in ankylosing spondylitis with thoracolumbar kyphotic deformity. Spine. 2005;30(14):1584-1593.

13. Peterson MD, Nelson LM, McManus AC, Jackson RP. The effect of operative position on lumbar lordosis. A radiographic study of patients under anesthesia in the prone and 90-90 positions. Spine. 1995;20(12):1419-1424.

14. Stephens GC, Yoo JU, Wilbur G. Comparison of lumbar sagittal alignment produced by different operative positions. Spine. 1996;21(15):1802-1806; discussion 1807.

15. Dorward IG, Lenke LG, Stoker GE, Cho W, Koester LA, Sides BA. Radiographical and clinical outcomes of posterior column osteotomies in spinal deformity correction. Spine. 2014;39(11):870-880.

16. Ricciardi L, Stifano V, Proietti L, et al. Intraoperative and postoperative segmental lordosis mismatch: analysis of 3 fusion techniques. World Neurosurg. 2018;115:e659-e663. doi: 10.1016/j.wneu.2018.04.126

17. Salem KMI, Eranki AP, Paquette S, et al. Do intraoperative radiographs predict final lumbar sagittal alignment following single-level transforaminal lumbar interbody fusion? J Neurosurg Spine. 2018;28(5):486-491.

18. Graham RB, Cotton M, Koht A, Koski TR. Loss of intraoperative neurological monitoring signals during flexed prone positioning on a hinged open frame during surgery for kyphoscoliosis correction: case report. J Neurosurg Spine. 2018;29(3):339-343.

Disclosures and COI: The authors received no funding for this study and report no conflicts of interest. The Institutional Review Board for Baylor College of Medicine and Affiliated Hospitals approved this study protocol.

Corresponding Author: Alexander E. Ropper, MD, Department of Neurosurgery, Baylor College of Medicine, 7200 Cambridge St, Suite 9A, Houston, TX 77030. Phone: (713) 798-4696; Fax: (713) 798-3739; Email: Alexander.Ropper@ bcm.edu.

Published 30 June 2020

This manuscript is generously published free of charge by ISASS, the International Society for the Advancement of Spine Surgery. Copyright (C) 2020 ISASS. To see more or order reprints or permissions, see http://ijssurgery.com. 